\title{
Weganizacja akademii i nowa humanistyka, czyli o weganizmie w kontekście badań literacko-kulturowych
}

Jeśli, jak twierdzi Andrew Linzey w przedmowie do Vegetarian America: A History autorstwa Karen Iacobbo i Michaela Iacobbo, „mięsożercy, którzy pisza historię, wykreślili z niej wegetarian [; i rzeczywiście] głos wegetarian jest prawie nieobecny $w$ badaniach humanistycznych", to w takim razie głos wegański pozostaje w jeszcze większym сіепiu [...].

Laura Wright ${ }^{1}$

U podstaw każdej utopii leży niezadowolenie.

Olga Tokarczuk ${ }^{2}$

\section{Od kuchni do akademii}

Na stronie internetowej poświęconej najnowszemu polskiemu słownictwu Obserwatorium Językowe Uniwersytetu Warszawskiego wyjaśnia, iż „weganizować” oznacza „wprowadzać takie zmiany do przepisu na danie zawierające mięso lub produkty pochodzenia zwierzęcego, żeby przyrządzić potrawę wegańską"3. Paradoks kuchni wegańskiej, znany każdemu, kto kiedykolwiek przygotowywał wegańską „pastę z makreli” lub wegański „omlet”, polega na tym, że usunięcie z niej kilku, wydawałoby się kluczowych, składników nie oznacza ograniczenia jej potencjału. W poszukiwaniu roślinnych zamienników składników zwierzę-

1. Laura Wright, The Vegan Studies Project. Food, Animals and Gender in the Age of Terror, The University of Georgia Press, Athens and London 2015, s. 8. [przeł. M.K.].

2. Olga Tokarczuk, Moment niedźwiedzia, Wydawnictwo Krytyki Politycznej, Warszawa 2012, s. 13.

3. Hasło ze słownika internetowego: „Weganizować”, w: Obserwatorium Językowe Uniwersytetu Warszawskiego. Najnowsze stownictwo polskie <http://www.nowewyrazy.uw.edu.pl/haslo/ weganizowac-zweganizowac.html> (3.09.2018). 
cych kuchnia wegańska wyzwala pokłady kulinarnej kreatywności i nie tylko przywraca smaki uznane przez wegan za utracone, ale również tworzy nowe. Weganizacja kuchni nie jest niczym innym niż procesem przekształcania potraw zawierających składniki zwierzęce w wersje zbliżone smakowo do oryginału, lecz bazujące na składnikach pochodzenia roślinnego. Innymi słowy, weganizacja to tradycja w nowej odsłonie, to kulinarny kanon na nowo odczytany i twórczo wykorzystany.

O ile weganizacja potraw na stałe weszła do repertuaru kuchni wegańskiej, a samo pojęcie zagościło na dobre $\mathrm{w}$ języku praktyki kulinarnej ${ }^{4}$, o tyle proces - na potrzeby niniejszego wywodu celowo określony w sposób hiperboliczny mianem weganizacji akademii - polegający na stopniowym budowaniu teorii wegańskiej, formułowaniu pytań dotyczących wegańskiego doświadczenia i jego reprezentacji oraz wprowadzaniu optyki wegańskiej do odczytywania tekstów kultury, znajduje się w fazie początkowej i w związku z tym domaga się szczególnego rodzaju refleksji. Gdy przenosimy ideę weganizacji na grunt akademii, w sposób nieunikniony pojawia się pytanie o to, czy rzeczywiście jest ona humanistyce potrzebna, i czy propozycja studiów nad weganizmem, które są kulminacyjnym przejawem owego procesu, nie jest naukowym nadużyciem skazującym badaczy skuszonych atrakcyjnością nowości na podążanie ślepą, a w najlepszym przypadku krótką uliczką. Aby odpowiedzieć na te pytania, warto prześledzić historię weganizacji nauk humanistycznych, podjąć próbę określenia specyfiki nowo powstałego obszaru oraz zastanowić się nad jego potencjałem badawczym i miejscem na mapie współczesnej humanistyki ${ }^{5}$.

\section{W stronę studiów nad wegீanizmem}

Gdybyśmy pozwolili naszej wyobraźni powołać do życia akademicki sejsmograf rejestrujący nowe „tektoniczne” ruchy intelektualne, zauważylibyśmy, że ostatnie dekady przyniosły znaczne ożywienie jego działalności. Nasz wyobrażony przyrząd zarejestrowałby zmiany, które przejawiają się, między innymi, w wyznaczaniu coraz to nowych obszarów badań humanistycznych. Studia nad płcią, ekokrytyka, ekofeminizm, studia nad zwierzętami czy studia afektywne to tylko niektóre z nowych przestrzeni, które uzyskały wyrazistą tożsamość i rozpoznawalność, wpisując się w humanistykę, którą wielu krytyków określa mianem nowej. Zda-

4. Po wprowadzeniu do wyszukiwarki słowa „veganisation”, otrzymujemy 27500 wyników. Polska „weganizacja” przynosi 2610 wyników (dane z 7.09.2018).

5. W polskojęzycznej literaturze krytycznej poświęconej studiom nad weganizmem ukazał się do tej pory jeden tekst Studia nad weganizmem - nowy obszar badawczy Dariusza Gzyry, „Edukacja Etyczna”, Kraków 2017, Wydawnictwo Naukowe Uniwersytetu Pedagogicznego. 
niem Ewy Domańskiej nową humanistykę cechuje „ostrze krytyczne wymierzone $\mathrm{w}$ dominujące dyskursy władzy oraz zaangażowanie w problemy społeczno-polityczne"6. Jak pisze autorka Historii niekonwencjonalnych nowa humanistyka jest "dyskursem interwencyjnym" ", który w centrum swojego zainteresowania badawczego stawia podmiot opresjonowany bądź też marginalizowany, budując wokół niego alternatywną wizję przyszłości oraz tworząc narzędzia teoretyczne niezbędne do opisu istniejących mechanizmów władzy/nierówności oraz do wyznaczania nowych kierunków rozwoju badawczego i społecznego.

Dzisiejsza humanistyka wydaje się świadkiem „wegańskiego zwrotu”, który jest przejawem rosnącego zainteresowania weganizmem i wyznaczania nowych kierunków na mapie współczesnych badań. Kilka przykładów zaczerpniętych ze światowego kalendarza wydarzeń akademickich obejmującego zarówno konferencje, jak i publikacje naukowe wskazuje na to, iż przez wielu badaczy naukowa refleksja nad weganizmem w kontekście badań humanistycznych zaczyna być postrzegana jako wartościowa i potrzebna. Pierwsza konferencja poświęcona teorii wegańskiej odbyła się w Oxfordzie w 2016 roku i nosiła tytuł „With their skins on them, and... their souls in them": Towards a Vegan Theory. An Interdisciplinary Humanities Conference. Rok później w Bostonie Association of American Geographers zorganizowało konferencję pod tytułem Towards Vegan Geographies: Ethics Beyond Violence ${ }^{8}$. Spotkaniom badaczy towarzyszą publikacje naukowe podejmujące kwestie związane z weganizmem w perspektywie badań literackich i kulturowych: warto wymienić w tym miejscu Critical Perspectives on Veganism pod redakcja Jodey Castricano i Rasmusa R. Simonsena (2016), Aphro-ism: Essays on Pop Culture, Feminism, and Black Veganism from Two Sisters autorstwa Aph Ko and Syl Ko (2017), Thinking Veganism in Literature and Culture. Towards a Vegan Theory (2018) pod redakcją Emelii Quinn i Benjamina Westwooda czy też numer ISLE: Interdisciplinary Studies in Literature and Environment (2017), w którym znalazła się cała sekcja poświęcona studiom nad weganizmem w kontekście ekokrytyki. W 2016 roku University of California w Santa Barbara uruchomił pierwszy program studiów nad weganizmem, który, jak czytamy w Santa Barbara Independent, przyciągnął tak wielu chętnych, iż prowadzący, profesor Renan Larue, poproszony został o podwojenie liczby miejsc 9 .

6. Ewa Domańska, O nowej humanistyce, „Litteraria Copernicana”, 2011, 1(7), s. 220.

7. Domańska, O nowej humanistyce, s. 220.

8. W maju 2018 roku Instytut Kultur i Literatur Anglojęzycznych Uniwersytetu Śląskiego zorganizował pierwsze ogólnopolskie seminarium pt. „Studia nad weg(etari)anizmem w kontekście badań literackich i kulturowych. Dylematy i perspektywy”. Większość tekstów składających się na niniejszy numer czasopisma stanowi rozbudowane wersje wystąpień przedstawionych podczas seminarium.

9. Léna Garcia, What Vegans Study, “Santa Barbara Independent”, 15.02.2016<https://www. independent.com/news/2016/mar/15/what-vegans-study> (4.09.2018). 
Nie jest przypadkiem, że wszystkie przytoczone powyżej przykłady akademickiej działalności spod znaku „wegańskiego zwrotu” miały miejsce po 2015 roku, który w historii weganizacji akademii ma znaczenie fundamentalne. W tym bowiem roku Laura Wright opublikowała monografię The Vegan Studies Project. Food, Animals and Gender in the Age of Terror ${ }^{10}$, otwierając tym samym drzwi do akademickiej dyskusji nad weganizmem w duchu cultural studies. Nie oznacza to rzecz jasna, że weganizm przed 2015 rokiem nie był poddawany oglądowi naukowemu. Coraz większa widoczność weganizmu w przestrzeni kulturowej (celebrytyzacja weganizmu, wegańscy bohaterowie kultury popularnej czy też wegańskie blogi i programy kulinarne) stworzyła warunki do zainicjowania debaty na temat kulturowych i filozoficznych aspektów diety roślinnej. W ostatnich latach nad aspektami odmowy spożywania produktów pochodzenia zwierzęcego zaczęli pochylać się badacze zajmujący się kulturową tożsamością płci, filozofowie, kulturoznawcy i psycholodzy. Oto kilka przykładów z długiej listy pozycji na temat wegetarianizmu i weganizmu: w 2009 roku Jonathan Safran Foer wydał Eating Animals, książkę poświęconą refleksji nad przemysłową produkcją mięsa, w ramach której osadził historię swojego wegetarianizmu; w roku 2010 Melanie Joy opublikowała książkę pt. Why We Love Dogs, Eat Pigs, and Wear Cows. An Introduction to Carnism wyjaśniającą mechanizmy kulturowe odpowiedzialne za tworzenie warunków, w których konsumpcja mięsa postrzegana jest jako normalna praktyka i w których niektóre gatunki otaczamy miłością, a inne zjadamy. Wprowadzona przez Joy koncepcja karnizmu natychmiast stała się jednym $\mathrm{z}$ najważniejszych elementów aparatu pojęciowego wypracowanego w celu analizy kulturowych i społeczno-politycznych aspektów weganizmu. Innym przykładem badań nad weganizmem, które rozwijały się przed 2015 rokiem, są prace analizujące związki pomiędzy weganizmem i kulturową reprezentacją męskości i kobiecości ${ }^{11}$ czy też aspekty weganizmu w kontekście rasy, uwarunkowań etnicznych i studiów postkolonialnych i dekolonialnych ${ }^{12}$.

W świetle wzrostu zainteresowania weganizmem - zarówno w wymiarze popularnym, jak i naukowym - stało się jasne, że w przestrzeni akademii rodzi się potrzeba zainicjowania systematycznych i zinstytucjonalizowanych badań nad kulturowo-polityczno-społecznymi aspektami weganizmu, dylematami,

10. Laura Wright, The Vegan Studies Project. Food, Animals and Gender in the Age of Terror, The University of Georgia Press, Athens and London 2015.

11. Zob. np.: John Joseph, Meat is for Pussies, Crush Books, New York 2010 i Justine Ann Johnson, "Hegans: An Examination of the Emerging Male Vegan" (2011). Theses, Dissertations, and Other Capstone Projects. Paper $124<$ https://cornerstone.lib.mnsu.edu/cgi/viewcontent. cgi?referer=https://www.google.com/\&httpsredir=1\&article=1123\&context=etos (10.09.2018).

12. Zob. np.: Sistah Vegan: Black Female Vegan Speak on Food, Identity, Health and Society pod redakcją Breeze Harper, Lantern Books, New York 2009. 
które ze sobą niesie i możliwością stworzenia i zastosowania teorii wegańskiej w przestrzeni badań humanistycznych. Formułując propozycję stworzenia odrębnego obszaru badań literacko-kulturowych poświęconego weganizmowi, Wright włączyła się w nurt tego, co w przestrzeni naukowej zaczęło powoli kiełkować i stopniowo przebijać się do świadomości badaczy reprezentujących różne obszary i metodologie. Istota propozycji Wright polega na tym, iż usytuowała weganizm w szerszym planie: wskazując na badawcze i naukowe „zadłużenie” studiów nad weganizmem wobec innych perspektyw i metodologii badawczych, zademonstrowała naukową odrębność i tożsamość nowo zarysowanego obszaru badawczego. Powołanie do życia nowych studiów wyrasta z przekonania autorki The Vegan Studies Project o konieczności wyodrębnienia podmiotu wegańskiego i stworzenia warunków, w których jego głos ma szansę wybrzmieć. Reakcja środowiska naukowego - a świadczą o niej chociażby niektóre ze wspomnianych powyżej wydarzeń ze świata akademii, powstałe z bezpośredniej inspiracji propozycją amerykańskiej badaczki - pokazuje, iż Wright znakomicie uchwyciła potrzebę stworzenia szerszej platformy dla debaty nad tożsamością wegańską oraz nad kulturowymi kontekstami weganizmu, który, postrzegany nie tylko jako styl życia, ale przede wszystkim jako ideologia i filozofia ${ }^{13}$, domaga się refleksji usytuowanej na przecięciu wielu perspektyw naukowych.

Jest rzeczą oczywistą, że studia nad weganizmem nie istnieją w naukowej próżni: drogę do ich powstania utorował rozwój studiów nad zwierzętami, ekokrytyki i ekofeminizmu oraz działalność ruchów na rzecz zwierząt. Wyłonienie się studiów nad weganizmem może być postrzegane jako przejaw tego, co Przemysław Czapliński, pisząc o nowej humanistyce, określa jako „autonomizacj[ę] problemów i kategorii ważnych, które wyłoniwszy się z poszczególnych dyscyplin, szybko zyskują samodzielność" ${ }^{14}$. Tak jak powstanie studiów kobiecych stworzyło warunki dla zainicjowania studiów nad kulturową tożsamością płci, tak studia nad zwierzętami, które rozpoczęły szeroko zakrojoną debatę nad relacjami pomiędzy człowiekiem i zwierzętami, z czasem wykazały konieczność pogłębienia badań nad jednym $z$ wielu elementów tej relacji - konsumpcji produktów pochodzenia zwierzęcego i jej kulturowo-ekonomiczno-politycznych uwarunkowań.

Jak przyznaje sama Wright, wywodzący się z tradycji cultural studies projekt ogromnie dużo zawdzięcza Carol J. Adams, która jako jedna z pierwszych badaczek

13. Tak weganizm definiowany jest w „Memorandum and Articles of Association”, dokumencie opublikowanym w 1979 roku przez The Vegan Society. Określenie weganizmu mianem filozofii nie jest jednak przyjmowane bezkrytycznie. Zob: Jonathan Dickstein, „Rethink Your Understanding of Veganism”, <https://medium.com/@jonathandickstein/rethink-your-understanding-of-veganism-39413185742> (22.10.2018).

14. Przemysław Czapliński, Sploty (Wstęp), „Teksty Drugie”, 1/2017<http://rcin.org.pl/dlibra/ publication $? \mathrm{id}=83938 \& \mathrm{tab}=3>(6.09 .2018)$. 
pochyliła się nad literackimi reprezentacjami związków pomiędzy zniewoleniem kobiet i wegetarianizmem ${ }^{15}$. Adams zaproponowała zastosowanie perspektywy badawczej, którą w mającej już status kanoniczny pracy The Sexual Politics of Meat (1990) określiła mianem feministyczno-wegetariańskiej teorii krytycznej. Odnosząc się do osiemnastowiecznych i dziewiętnastowiecznych tekstów literackich Adams pokazuje, że feminizm i wegetarianizm wiele łączy i mówi wprost: nasze posiłki albo ucieleśniają, albo negują zasady feministyczne poprzez rodzaj pożywienia, które wybieramy. Jej zdaniem zarówno pisarze/pisarki, jak i poszczególne jednostki wpisują w kontekst wegetariański głębokie feministyczne deklaracje. Wegetarianizm w życiu i twórczości kobiet przywołanych przez Adams jest wyrazem ich niezależności oraz formą protestu wobec kultury dominującej bez względu na to, czy jest czy też nie jest jako taki określany ${ }^{16}$.

To, co w pracy Adams wydaje się niezwykle istotne z punktu widzenia metodologicznego osadzenia literackich i kulturowych studiów nad weganizmem, to zwrócenie uwagi na fakt istnienia feministyczno-wegetariańskiej tradycji literackiej. Adams kieruje snop badawczego światła na różnorodne teksty literackie i uwidacznia ich wspólne wegetariańsko-feministyczne elementy. Mary Astell, Margaret Cavendish, Aphra Behn, Mary Wollstonecraft - to tylko niektóre z pisarek, w których życiu i twórczości pojawia się kwestia konsumpcji mięsa wpisana w kontekst kulturowej opresji kobiet. Jak zauważa Adams, feministyczno-wegetariańska teoria krytyczna zaczyna się w momencie, w którym uświadamiamy sobie podobieństwo $\mathrm{w}$ pozycjonowaniu kobiet i zwierząt $\mathrm{w}$ świecie patriarchalnego porządku: i kobiety, i zwierzęta funkcjonują jako przedmioty, nigdy jako podmioty ${ }^{17}$. W ujęciu Adams zarówno kobiety, jak i zwierzęta poddawane są kulturowemu „uniewidocznieniu”, funkcjonując w strukturach patriarchatu jako „nieobecny punkt odniesienia” (absent referent). Adams nie ma wątpliwości, że taki stan rzeczy domaga się zjednoczenia myśli feministycznej i wegetariańskiej ${ }^{18}$. Perspektywa Carol J. Adams okazała się ogromną inspiracją dla badań prowadzonych w obszarze feminizmu, ekofeminizmu oraz studiów nad zwierzętami. Istotnym dla naszych rozważań nad studiami nad weganizmem jest fakt, iż praca Adams stanowiła w pewnym sensie punkt odniesienia czy też naukowy

15. Wright, The Vegan Studies Project, s. 18. Warto w tym momencie zwrócić uwagę na posługiwanie się przez amerykańską badaczkę określeniem „projekt”: Wright podkreśla w ten sposób, iż studia nad weganizmem znajdują się w fazie formatywnej i w związku z tym zapraszają do debaty na temat swojej tożsamości, metodologii i perspektyw dalszego rozwoju.

16. Carol J. Adams, The Sexual Politics of Meat. A Feminist-Vegetarian Critical Theory, Polity Press, Cambridge 1990, s. 166-167.

17. Adams, The Sexual Politics of Meat, s. 168.

18. Adams, The Sexual Politics of Meat, s. 169. Zob. również: Greta Gaard, Vegetarian Ecofeminism, "Frontiers", 2002,3/23, s. 117-146. 
drogowskaz dla autorki The Vegan Studies Project. Autorką słowa wstępnego do książki Wright była właśnie Adams, która udzieliła jej swego akademickiego błogosławieństwa, podkreślając, iż jest ona kontynuatorką pracy zainicjowanej przez The Sexual Politics of Meat.

Monografia Wright poświęcona wyodrębnieniu tożsamości wegańskiej i usytuowaniu jej w szerszym kontekście badań literacko-kulturowych jest osadzona na fundamentach wzniesionych przez Adams - wykorzystując metodologię zastosowaną przez autorkę The Sexual Politics of Meat, rozbudowuje analizę mechanizmów kulturowego przekształcania zwierzęcia w nieobecny punkt odniesienia i osadza weganizm w polu badań nad reprezentacjami kulturowej tożsamości płci we współczesnej kulturze oraz relacjami władzy. Podczas gdy Adams w swojej pracy wyszła od założenia normatywności wegetarianizmu i analizy sposobów, za pomocą których kultura dominująca tę normatywność unieważnia, Wright zakłada normatywność weganizmu i pokazuje, że teoria feministyczna jest potrzebna, aby zrozumieć, w jaki sposób kultura dominująca sprawia, że aspekt etyczny weganizmu znika, poszerzając tym samym badania Adams nad nieobecnym punktem odniesienia. Do trzech sposobów, za pomocą których kultura doprowadza do znikania zwierząt, Wright dodaje kolejny: promocja weganizmu jako stylu życia usuwa w cień i marginalizuje kwestie etyczne związane z prawami zwierząt.

Istotą badań prowadzonych przez Wright jest to, iż proponuje ona ujęcie rozważań nad kulturowymi kontekstami weganizmu w ramy studiów nad weganizmem. Jeśli mamy jednak mówić o studiach, to określeniu ich specyfiki towarzyszyć powinna przede wszystkim próba odpowiedzi na pytanie, czym jest weganizm. Nie jest przypadkiem, że zarówno Laura Wright w swoim eseju Introducing Vegan Studies ${ }^{19}$, jak i Emelia Quinn i Benjamin Westwood, redaktorzy zbioru pt. Thinking Veganism in Literature and Culture ${ }^{20}$, zaczynają swoje rozważania nad weganizmem od definicji słownikowych. Zabieg ten - zasadny, wręcz fundamentalny, w kontekście budowania tożsamości nowo powstałego obszaru badań - ma jednak pewną skazę: wskazując na jedną, wielokrotnie powtarzaną definicję weganizmu usuwa w badawczy cień fakt, iż obecnie mamy do czynienia z różnorodnością ujęć weganizmu i jego popkulturowych odsłon. Wydaje się, że w sytuacji swego rodzaju pluralizmu tożsamościowego jednym z podstawowych problemów badawczych, jakie pojawiają się przed studiami nad weganizmem,

19. Laura Wright, Introducing Vegan Studies, "ISLE: Interdisciplinary Studies in Literature and Environment", 2017, Volume 24, Issue 4. <http://www.academia.edu/35622783/Introducing_Vegan_Studies._nterdisciplinary_Studies_in_Literature_and_Environment_00.0_2017_ pp._1_10doi_10.1093_isle_isx070> (10.09.2018).

20. Emelia Quinn, Benjamin Westwood, Introduction: Thinking Through Veganism, w: Thinking Veganism in Literature and Culture. Towards a Vegan Theory, Palgrave Macmillan 2018, s. 1. 
jest wskazanie na różnorodność definicji weganizmu i tego, co z tej różnorodności wynika dla samego weganizmu rozumianego jako ruch na rzecz społecznej sprawiedliwości oraz dla prowadzonych nad nim badań. Nie bez powodu Wayne Hsiung, współzałożyciel Direct Action Everywhere, zauważa, iż „weganizm ma zdumiewającą liczbę definicji, podobnie jak zdumiewająca jest liczba motywów, które powodują, że ludzie decydują się na przejście na dietę wegańską" ${ }^{21}$.

To, czym weganizm jest i to, czym nie jest, ma znaczenie nie tylko w kontekście wyznaczenia pola badawczego, ale również w kontekście debaty na temat skuteczności weganizmu jako narzędzia walki o prawa zwierząt. Studia nad weganizmem stanowić mogą platformę wymiany perspektyw i ścierania się różnych, często wykluczających się wizji tego, czym jest weganizm i jaką formę powinien przyjmować. Robert C. Jones $\mathrm{w}$ artykule pod wiele mówiącym tytułem „Veganisms” („Weganizmy”) wyróżnia dwie główne odmiany. Pierwsza z nich to weganizm tożsamościowy (identity weganism), określany jako styl życia, który cechuje nieco naiwna wiara, że samo przejście na weganizm rozwiązuje kwestie związane z okrucieństwem wobec zwierząt i ich cierpieniem, i który ignoruje fakt, iż produkcji wegańskich towarów często towarzyszy cierpienie zwierząt. Jest on nierzadko wyznacznikiem modnego i nowoczesnego stylu życia, elementem "zestawu obowiązkowego" dla osób pragnących żyć w zgodzie z obowiązującymi trendami, chcących zachować czyste sumienie i jednocześnie demonstrować swoją moralną wyższość wobec nie-wegan ${ }^{22}$. Drugi typ weganizmu to weganizm bojkotowy (boycott veganism), którego zwolennicy, mający poszerzoną świadomość dotyczącą produkcji wielu wegańskich towarów, która pociąga za sobą cierpienie zwierząt, postrzegają swoje własne wybory konsumenckie jako mające moc sprawczą. Jak pisze Jones, zwolennicy weganizmu bojkotowego podzielają przekonanie, że „»głosowanie« wegańskimi dolarami może przyczynić się to realnego rozwoju moralnego i wywołać zmianę polityczną" ${ }^{23}$, demonstrując jednocześnie pewną krótkowzroczność, która nie pozwala na wpisanie weganizmu w szerszy obraz opresjonowania żyjących istot oraz zagrożeń ekologicznych.

Pozostając krytycznym wobec dwóch dominujących odmian weganizmu, Jones proponuje wprowadzenie kategorii rewizyjnego weganizmu politycznego (revisionary political veganism), którego głównymi wyznacznikami są rewizyjność, aspiracyjność, intersekcjonalność i inkluzywność ${ }^{24}$. Jones proponuje w pewnym sensie najszersze rozumienie weganizmu: weganizm polityczny w jego ujęciu

21. Wayne Hsiung, Boycott Veganism <http://www.images.pythagoreancrank.com/boycott_veganism.pdf> (9.09.2018).

22. Robert C. Jones, Veganisms, w: Critical Perspectives on Veganism, red. Jodey Castricano i Rasmus R. Simonsen, Palgrave Macmillan 2016, s. 25.

23. Jones, Veganisms, s. 27. [Przeł. M.K.].

24. Jones, Veganisms, s. 26-32. 
oznacza „moralne i polityczne zobowiązanie do aktywnego sprzeciwu wobec form insty tucjonalnej i systemowej przemocy, wyzysku, dominacji, uprzedmiotowienia i utowarowienia wymierzonych wobec wszystkich odczuwających istot - ludzkich i pozaludzkich - jak również wobec środowiska naturalnego, które zapewnia im ciągłość życia"25. Tak rozumiany weganizm, w zasadniczy sposób poszerzający "tradycyjną" definicję, staje się strategią walki z niesprawiedliwością społeczną, której ofiarami padają nie tylko zwierzęta, ale co istotne, również ludzie.

Interesujący głos $\mathrm{w}$ debacie na temat istoty weganizmu należy do Hsiunga, który uważa, iż „weganizm jest szkodliwy dla ruchu na rzecz praw zwierząt” i idąc tym tropem, twierdzi, że tym, co powinno się bojkotować w imię wyzwolenia zwierząt, nie są produkty pochodzenia zwierzęcego, lecz weganizm ${ }^{26}$. Tak kontrowersyjne stanowisko wynika z przekonania powszechnie przypisywanego weganom, iż przejście na weganizm jest sposobem na zaprzestanie przemysłowej hodowli zwierząt. Uproszczona, popularna wersja weganizmu jest bez wątpienia naiwna, ale czy rzeczywiście jest szkodliwa? Dla Hsiunga „szkodliwość” weganizmu polega na tym, iż decyzja o przejściu na dietę bezmięsną jest swego rodzaju laurem, który weganie wkładają sobie na głowę w nagrodę za podjęcie moralnie słusznej decyzji... i na tym kończą swoje zaangażowanie w wyzwolenie zwierząt. Zwolennicy diety wegańskiej zaprzestają walki o prawa zwierząt w miejscu, w którym owa walka tak naprawdę się zaczyna, bowiem zmiana diety jest zaledwie początkiem procesu przemian. Zdaniem Hsiunga, weganizm ani nie ratuje życia, ani nie zmniejsza cierpienia zwierząt, a przedstawiany jako wybór stylu życia sytuuje kwestię cierpienia zwierząt w cieniu deklaracji o upodobaniu do diety bezmięsnej postrzeganej jako atrybut wizerunkowy. Konieczność uświadomienia sobie tego faktu może być początkiem większego zaangażowania w walkę o prawa zwierząt - potrzebne jest jednak zainicjowanie rzeczowej debaty na ten temat i tutaj studia nad weganizmem mogą stać się ważną przestrzenią wymiany poglądów.

Potencjał badawczy studiów nad weganizmem wynika $\mathrm{z}$ faktu, że nie zawężają one własnego obszaru do ,jedynie słusznej”, etycznie umotywowanej ideologii (weganizm etyczny), ale przedmiotem swoich rozważań czynią literackie i kulturowe reprezentacje i aspekty weganizmu w jego zróżnicowanych odsłonach. Wyjście poza obszar badawczy studiów nad zwierzętami czy też ekofeminizmu, które to perspektywy, jak już wspomnieliśmy, mają dla studiów nad weganizmem znaczenie fundamentalne, pozwala na wpisanie refleksji nad dietą wegańską w jeszcze szerszy kontekst. Próby określenia, czym jest weganizm i jakie są motywy, które kierują tymi, którzy odrzucają konsumpcję produktów pochodzenia roślinnego, otwierają nowe przestrzenie badawcze i poszerzają te już

25. Jones, Veganisms, s. 29.

26. Hsiung, Boycott Veganism. [Przeł. M.K.]. 
istniejące. Fakt, iż w warunkach kultury Zachodu dieta bezmięsna funkcjonuje jako kulturowy rekwizyt białej klasy średniej, sprawia, że wpisanie weganizmu w kontekst badań dekolonizacyjnych odsłania cały szereg związków pomiędzy konsumpcją, tożsamością etniczną i płcią. „Czarny” weganizm to różnorodność motywów stojących za wyborem diety wegańskiej oraz dialog z białą kulturą dominującą; to pytanie o to, czy czarni weganie/weganki są "produktem” białych praktyk kolonizacyjnych (czarni weganie/weganki przejmują styl życia białej uprzywilejowanej klasy średniej) czy też w geście intersekcjonalnego protestu stają się wyrazicielami sprzeciwu wobec nakładających się na siebie i wzajemnie się napędzających struktur opresji. Te zależności - pomiędzy rasą, klasą, płcią i weganizmem - nabierają kształtów w obrębie studiów nad weganizmem $\mathrm{z}$ tego względu, iż perspektywa badawcza tego obszaru pozwala na ich dogłębną analizę oraz na usytuowanie ich w pozycji dialogicznej wobec innych dyskursów.

Rozważania poświęcone wspomnianym powyżej związkom wpisują się w nurt, który stanowi istotę studiów nad weganizmem, a który wyznaczany jest przez kwestie reprezentacji weganizmu zarówno w powszechnej świadomości, jak i w szeroko rozumianych tekstach kultury (film, literatura, media społecznościowe, blogi). Badania prowadzone przez Wright odsłaniają potencjał perspektywy wegańskiej i jej różnorodność. Dla autorki The Vegan Studies Project punktem wyjścia do analizy reprezentacji weganizmu w kulturze jest wojna z terrorem ogłoszona przez George’a W. Busha po ataku na World Trade Center. To na pierwszy rzut oka zaskakujące połączenie okazuje się jednak ważnym kluczem do zrozumienia mechanizmów znaczeniotwórczych, które zostały uruchomione po jedenastym września 2001 roku w kontekście konstruowania tożsamości amerykańskiej i podziału na „my” i „oni” oraz ich związków z konsumpcją. Optyka wegańska zastosowana przez Wright pozwala na zarejestrowanie istotnej zmiany, której uległa reprezentacja weganizmu w powszechnej świadomości. Weganizm, zyskujący w ostatnich dekadach XX wieku coraz większą popularność i coraz bardziej widoczny w przestrzeni publicznej, po jedenastym września stał się swego rodzaju ofiarą retorycznego podziału wprowadzonego przez rząd Busha jako nie-amerykański wybór dietetyczny ${ }^{27}$. Wobec powstania nowej narodowej narracji, której celem było odbudowanie poczucia siły tożsamości amerykańskiej - a ta przejawia się również w (mięsnej) tradycji kulinarnej - dieta wegańska zaczęła być kojarzona $\mathrm{z}$,fundamentalizmem, radykalizmem i protestami antyrządowymi”28.

Powracając do sformułowanego na początku naszych rozważań pytań o zasadność powoływania do życia nowych studiów: wydaje się, że studia nad weganizmem mogą odegrać ważną rolę na kilku płaszczyznach. $Z$ jednej strony

27. Wright, The Vegan Studies Project, s. 30.

28. Wright, The Vegan Studies Project, s. 42 [Przeł. M.K.].. 
studia nad weganizmem pozwalają zidentyfikować wewnętrzne tarcia w obrębie weganizmu i wpisać je w kontekst toczącej się debaty na temat gatunkizmu, zrównoważonego stylu życia, ekologii, feminizmu i studiów postkolonialnych i dekolonialnych. Co więcej, wyznaczenie obszaru badawczego poświęconego weganizmowi pozwala na pogłębienie debaty na temat skuteczności weganizmu etycznego (a więc tego, który motywowany jest dobrem zwierząt) jako narzędzia walki o prawa zwierząt. Tak rozumiane studia dają możliwość prześledzenia zmian jakim podlega myślenie o weganizmie jako „dyskursie interwencyjnym”, jego społeczno-politycznych konsekwencjach i skuteczności. Idąc tropem wyznaczonym przez tak sformułowany cel badawczy, zauważamy, iż we współczesnej debacie coraz częściej pojawia się określenie „post-weganizmu”, rejestrujące ewolucję rozumienia, czym jest weganizm i jakie formy przyjmuje. Tobias Leenaert, współzałożyciel ProVegInternation oraz autor How to Create a Vegan World: A Pragmatic Approach, w artykule umieszczonym na swoim blogu wskazuje na zasadność przejścia do fazy post-weganizmu, którą cechuje mniejsza dbałość o przestrzeganie rygorystycznych zasad żywieniowych lecz większe zainteresowanie rzeczywistą poprawą sytuacji zwierzą ${ }^{29}$. Peter Singer, autor wstępu do How to Create a Vegan World, zauważa, że jeśli weganizacja świata ma zależeć od tego, czy wybieramy altruizm czy własny interes i przyjemność, to nasza przyszłość będzie, w najlepszym wypadku, zaledwie w części wegańska ${ }^{30}$. Leenaert ma świadomość, iż apelowanie do altruizmu człowieka jest mało skuteczne i w związku z tym każda forma ograniczenia spożywania mięsa - czy to w ramach kampanii reduktarianistycznych, czy też wprowadzenia pewnej mody na niejedzenia mięsa - powinna zasługiwać na wsparcie, bo jak mówi Leenaert, „niejedna droga prowadzi do Veganville"31.

Druga płaszczyzna, na której studia nad weganizmem zarysowują swoją odrębność i tożsamość naukową, obejmuje wypracowanie transdyscyplinarnej teorii wegańskiej, która pozwala na zbudowanie optyki badawczej stawiającej w centrum zainteresowania pozycję wegańskiego podmiotu i jego reprezentację. Warto w tym momencie powrócić do rozważań Czaplińskiego na temat charakteru nowoczesnej humanistyki. Zauważa on, że obszary badawcze określane dzisiaj mianem „nowej humanistyki” cechuje brak wspólnej metody, którą zastępują „semimetody” wypracowywane na własne potrzeby przez poszczególne obszary badawcze. Jak pisze Czapliński, „[p]owstające semimetody, choć wyosobniły się ze swoich dziedzin macierzystych, nie trwają w izolacji, lecz z konieczności włączają się w inne konstelacje

29. Tobias Leenaert, Go Post-Vegan!, „The Vegan Strategist”'<http://veganstrategist.org/2016/11/03/ go-post-vegan/?doing_wp_cron=1539324969.9043428897857666015625> (12.10.2018).

30. Peter Singer, Foreword, w: Tobias Leenaert, How to Create a Vegan World: A Pragmatic Approach, Lantern Books, New York 2017. Wydanie elektroniczne.

31. Leenaert, How to Create a Vegan World [Przeł. M.K.]. 
i same przyłączają do siebie elementy innych metod"32. Centralną metaforą, która pozwala uchwycić specyfikę nowej humanistyki w kontekście metodologicznym, są w ujęciu Czaplińskiego sploty, które niosą ze sobą ideę łączenia, przenikania i współistnienia. Jego zdaniem „[s]ploty metodologiczne nie są więc przypadkiem, lecz cechą kluczową dla uprawiania nauki”33.

Sploty, o których pisze Czapliński, widać wyraźnie w przypadku studiów nad weganizmem, które z racji swego badawczego umocowania czerpią z metodologii wielu obszarów badawczych. Wspomniane już „semimetody” są w perspektywie Czaplińskiego „z definicji niedomknięte: stan niekompletności pomaga badaczom pozostawać w kontakcie ze zmienną - płynną, niestałą - ontologią przedmiotów własnych badań, choć skazuje ich na ustawiczne zalepianie dziur"34. O ile w początkowej fazie rozwoju badania nad weganizmem obejmowały głównie aspekty dietetyczne, o tyle dzisiaj weganizm - ontologicznie niestały i poszerzający swoje znaczenie - wymusza refleksję metodologicznie osadzoną w dyskursach feministycznym, ekokrytycznym, zwierzęcym, postkolonialnym i antyglobalistycznym. Poddane wegańskiemu oglądowi teksty kultury odsłaniają relacje i uwarunkowania, które do tej pory nie były zauważane, czego przykładem może być wspomniana już reprezentacja weganizmu w kontekście wojny z terrorem ogłoszona przez Busha. Transdyscyplinarny charakter studiów nad weganizmem przejawia się $\mathrm{w}$ tym, iż badania prowadzone w obrębie innych dyscyplin pomagają wytworzyć narzędzia niezbędne do opisu skomplikowanych kontekstów weganizmu, które ciągle ewoluują, co pociąga za sobą ciągły rozwój myśli wegańskiej.

Przykładem, który ilustruje fakt, iż istnieje potrzeba ciągłej weryfikacji stosowanych narzędzi, może być neokarnizm, które to pojęcie Joy, autorka koncepcji karnizmu, wprowadziła dla opisania całego szeregu nowych praktyk kulturowych skierowanych do tych wszystkich, którzy zaczęli odczuwać wątpliwości dotyczące konsumpcji mięsa, ale nie chcą z niego zrezygnować. Żywność pochodząca od „szczęśliwych” zwierząt, produkty mięsne określane mianem „organicznych” lub „ekologicznych”, bezmięsne dni tygodnia - to tylko niektóre przykłady z długiej listy strategii kulturowych mających na celu rozładowanie wewnętrznych napięć doświadczanych przez tych konsumentów, którzy czując się zobowiązani przez, na przykład, presję środowiska, do wykazania troski o dobrostan zwierząt, nie potrafią zrezygnować z konsumpcji mięsa. Innym przykładem, również z obszaru psychologii, który pokazuje, jak wiele dzieje się obecnie w obszarze studiów humanistycznych w kontekście badań nad weganizmem, jest praca Clare Mann nad psychologicznymi aspektami bycia na diecie

32. Czapliński, Sploty.

33. Czapliński, Sploty.

34. Czapliński, Sploty. 
wegańskiej. Badania psychologiczne przeprowadzone pośród wegan na całym świecie wskazują na istnienie problemu, który Mann określiła mianem vystopia („wystopia”). Zdaniem autorki Vystopia. The Anguish of Being Vegan Po a Non-Vegan World (2018) „wystopia” oznacza (1) kryzys egzystencjalny doświadczany przez wegan, wyrastający ze świadomości istnienia hipnotycznej zmowy dystopijnego świata oraz (2) świadomość zachłanności, wszechobecnego cierpienia zwierząt oraz gatunkizmu we współczesnej dystopii ${ }^{35}$. Dla wielu wegan świadomość życia w świecie, w którym zdecydowana większość jest mięsożerna, w którym bardzo często dieta wegańska jest przedmiotem komentarzy, i której nierzadko towarzyszy brak zrozumienia pośród najbliższych oraz poczucie braku wsparcia, bywa źródłem głębokiego niepokoju. Nazwanie tego, czego doświadcza wielu wegan jest formą nadania ważności ich odczuciom. Wystopia, jak podkreśla Mann, nie jest schorzeniem ani patologią, ale formą egzystencjalnej rozpaczy której rozpoznanie i nazwanie dla wielu wegan może stanowić istotny krok w kierunku jej przezwyciężenia ${ }^{36}$.

Wyznacznikiem nowej humanistyki są badania prowadzone przez psychologów, filozofów, kulturoznawców i literaturoznawców, które - jak pisze Czapliński - przenikają się, tworząc warunki do studiowania „wielości linii przebiegających przez jeden punkt” oraz „śledzeni[a] mnogości śladów tam pozostawionych” ${ }^{37}$. Widziane w kontekście metodologii nowej humanistyki studia nad weganizmem są "przestrzenią niedomkniętą", której granice są płynne i nieszczelne, ale to właśnie ta nieszczelność stanowi zaproszenie do badania różnorodnych tropów i wsłuchiwania się w głosy jeszcze do niedawna prawie wcale nie słyszane.

\section{Weganizacja akademii \\ w kontekście humanistyki prefiguratywnej}

Przywołana na początku artykułu Ewa Domańska, mówiąc o aspektach nowej humanistyki, proponuje wprowadzenie pojęcia „humanistyki prefiguratywnej”, która w jej ujęciu tworzy obrazy przyszłości „,"zawczasu«; niejako zwiastuje jej nadejście, a jednocześnie bierze udział w kształtowaniu możliwych scenariuszy przyszłości [...]”. Domańska pisze, iż „[...] chodzi tu nie tyle o krytykę istniejącego systemu, ile o konkretne eksperymenty w tworzeniu alternatywy dla systemu, który jest uważany (z różnych względów) za wadliwy, niesprawiedliwy; o prak-

35. Clare Mann, Vystopia. The Anguish of Being Vegan Po a Non-Vegan World, Communicate31 Pty Ltd., Sydney 2018. Wydanie elektroniczne.

36. Mann, Preface, w: Vystopia. Wydanie elektroniczne.

37. Czapliński, Sploty. 
tykowanie konkretnych inicjatyw i pokazywanie w ten sposób, że zmiana jest możliwa" ${ }^{38}$. Zdaniem Domańskiej tym, co wyznacza kierunek badań w obrębie humanistyki prefiguratywnej, a więc humanistyki zaangażowanej, jest nie/sprawiedliwość epistemiczna ${ }^{39}$. Pojęcie wprowadzone do współczesnego dyskursu w 2007 roku przez Mirandę Fricker w Epistemic Injustice: Power and the Ethics of Knowing ${ }^{40}$ odsłania wpływ relacji władzy na proces budowania wiedzy oraz na podmiot badający i badany. W przedstawionym w swoim artykule omówieniu koncepcji zaproponowanej przez Fricker Domańska wpisuje nie/sprawiedliwość epistemiczną w kontekst studiów postkolonialnych i geopolityki wiedzy, podnosząc kwestię statusu polskiej wiedzy i jej peryferyjnego charakteru oraz postulując dekolonizację polskiej nauki.

Tym, co jest szczególnie interesujące dla naszych rozważań na temat miejsca badań nad weganizmem w ramach nowej humanistyki, jest możliwość przeniesienia koncepcji epistemicznej nie/sprawiedliwości na grunt debaty o relacjach człowiek-zwierzę, a w szczególności zaś na grunt refleksji na temat kulturowych i politycznych uwarunkowań diety mięsnej i roślinnej i jej reprezentacji we współczesnej kulturze. Takie przeniesienie pozwala na sformułowanie tezy o systemowym wykluczaniu zwierząt ze wspólnoty epistemicznej i stwarza punkt wyjścia do wskazania przykładów niesprawiedliwości epistemicznej, która stanowią podstawę karnistycznych praktyk kulturowych. Kartezjańskie twierdzenie, że zwierzęta nie odczuwają bólu, jest przykładem epistemicznej niesprawiedliwości świadczenia (testimonial epistemic injustice), podobnie jak twierdzenie, iż zwierzęta idące na rzeź nie mają świadomości tego, co je czeka. Niesprawiedliwość epistemiczna przejawia się również w kulturowym uzasadnianiu konieczności zabijania zwierząt $\mathrm{w}$ celach konsumpcji oraz $\mathrm{w}$ systemowych mechanizmach „uniewidocznienia” wiedzy na temat tego, w jaki sposób zwierzęta postrzegane jako surowce są przez człowieka używane i zużywane. Niedopuszczanie do siebie wiedzy na temat, przykładowo, pochodzenia i zindywidualizowanej historii zwierzęcia, którego ciało staje się przedmiotem konsumpcji, jest formą tego, co José Medina określa mianem „aktywnej ignorancji”. Według autora The Epistemology of Resistance: Gender and Racial Oppression, Epistemic Injustice, and the Social Imagination jest to „ten rodzaj ignorancji, która ma zdolność do ochrony samej siebie, mając do dyspozycji całą baterię mechanizmów obronnych (psychologicznych i politycznych), które mogą sprawić, że jednostki i grupy stają się nie-

38. Ewa Domańska, Sprawiedliwość epistemiczna w humanistyce zaangażowanej, „Teksty Drugie", 2017, 1/2017, s. 49.

39. Domańska, Sprawiedliwość epistemiczna..., s. 42.

40. Miranda Fricker, Epistemic Injustice: Power and the Ethics of Knowing, Oxford University Press, Oxford 2007. 
czułe na pewne zjawiska i dowody oraz niezdolne do pobierania nauki w tych obszarach"41. Medina mówi o ideologiach rasistowskich i seksistowskich, które ograniczają nasze możliwości poznawcze ${ }^{42}$, ale podobny mechanizm dostrzegamy, gdy w grę wchodzi gatunkizm i przekonanie o nieograniczonej władzy człowieka nad środowiskiem naturalnym. Strategie obronne gatunkizmu obejmują, między innymi, wspomniane już karnistyczne praktyki kulturowe oraz te działania, które jak zauważyła Adams, przekształcają zwierzęta w nieobecny punkt odniesienia. Konfrontacja z hermeneutyczną niesprawiedliwością epistemiczną (hermeneutical epistemic injustice) w kontekście weganizmu pozwala na skierowanie poznawczego światła na te elementy praktyk kulturowych, które w imię utrwalania istniejących znaczeń i schematów zostają poddane procesowi usuwania z pola powszechnej świadomości. Innym aspektem tej konfrontacji może być podjęcie próby wyposażenia podmiotu wegańskiego w narzędzia opisu własnej kondycji. I tak, przykładowo, wspomniana już wystopia wpisana w kontekst hermeneutycznej nie/sprawiedliwości epistemicznej może być postrzegana jako forma „uzbrojenia” podmiotu doświadczającego kryzysu egzystencjalnego na tle dystopijnego charakteru relacji człowiek-zwierzę w aparat pojęciowo-poznawczy, za pomocą którego może dokonywać się jego przezwyciężenie. Poszerzenie wiedzy psychologicznej o aspekty związane z decyzją o przejściu na dietę roślinną stanowi ważny krok w kierunku zniesienia ograniczeń epistemicznych dzięki tworzeniu warunków pozwalających na rozwinięcie krytycznego podejścia do kwestii społecznego odbioru weganizmu.

Weganizacja akademii widziana w kontekście epistemicznej nie/sprawiedliwości może być rozumiana jako element nowej humanistyki, przed którą stają nowe wyzwania i nowe zadania, i której celem jest zmierzenie się z tym, co Medina określa mianem „epistemicznych deficytów”43. Analiza relacji władzy i wiedzy, sposobów, w jakie władza konstruuje wiedzę o aspektach diety mięsnej i roślinnej, obrazów, za pośrednictwem których ją rozpowszechnia, oraz stworzenie ramy teoretycznej dla dyskursu odsłaniającego mechanizmy tej relacji stanowią najpoważniejsze aspekty studiów nad weganizmem.

Na szczególną uwagę w ujęciu zaproponowanym przez Domańską zasługuje wpisanie rozważań o zadaniach nowej humanistyki w kontekst dyskursu utopijnego, który odsłaniając swój światotwórczy potencjał, pokazuje, że utopia i myślenie utopijne są nam dzisiaj potrzebne bardziej niż kiedykolwiek. Potrzebne jest jednak nowe myślenie o utopii, swego rodzaju rehabilitacja pojęcia, które

41. José Medina, The Epistemology of Resistance: Gender and Racial Oppression, Epistemic Injustice, and the Social Imagination, Oxford University Press, New York 2013, s. 58 [Przeł. M.K.].

42. Medina, The Epistemology of Resistance..., s. 27.

43. Medina, The Epistemology of Resistance..., s. 28. 
w popularnym rozumieniu oznacza projekt skazany na niepowodzenie ze względu na oderwanie od rzeczywistości i pozostawanie w sferze wyobraźni. Według Domańskiej, celem humanistyki prefiguratywnej jest „kreowanie krytycznej nadziei” na stworzenie alternatywnej wizji przyszłości, która jest formą „realistycznej utopii" ${ }^{4}$. Humanistykę prefiguratywną, zaangażowaną, cechuje myślenie utopijne w tym sensie, że jak mówi cytowany przez Domańską Frederic Jameson, „utopia jako forma, nie jest przedstawieniem radykalnych alternatyw; jest raczej nakazem, aby je sobie wyobrażać" ${ }^{\prime 4}$. Nową humanistykę - dotyczy to również studiów nad weganizmem - określa więc dążenie do wyobrażenia sobie innego, ulepszonego systemu społeczno-polityczno-kulturowego, przy czym podkreślić należy, że w dyskursie nowej humanistyki ogromne znaczenie przypisuje się sprawczości na poziomie jednostkowym. Domańska deklaruje: „[...] skłaniam się ku realistycznym mikroutopiom, które mogą być urzeczywistniane w ograniczonej czasowo i przestrzennie skali lokalnej, jako obowiązujące w określonym czasie, na potrzeby konkretnej społeczności dla wspomożenia dobrostanu jej członków"46. Istota deklaracji Domańskiej widziana z punktu widzenia badaczy zajmujących się studiami nad zwierzętami, ekokrytyką czy studiami nad weganizmem pociąga za sobą redefinicję pojęcia „społeczności” i konieczność poszerzenia jej o podmioty pozaludzkie. „Dobrostan” pozaludzkich członków nowo określonej wspólnoty leży u podstaw projektu alternatywnej przyszłości. Jeszcze raz oddajmy głos Ewie Domańskiej:

W sferze dyskursu można myśleć o ich [realistycznych mikroutopii, przyp. M.K.] odnajdowaniu lub budowaniu w ramach sterowanej ideami epistemicznej sprawiedliwości humanistyki prefiguratywnej, afirmatywnej, tj. takiej która w kulturze i życiu społecznym identyfikuje konkretne (i często innowacyjne) praktyki i rodzaje relacji mogące stanowić podstawy budowania lepszych modeli wspólnotowości i współbycia ${ }^{47}$.

„Wspólnotowość" i „współbycie” wyznaczają kierunek badań nowej humanistyki i kierunek działania. W zbiorze esejów pt. Moment niedźwiedzia Olga Tokarczuk zaprasza do wzięcia udziału w grze towarzyskiej, którą określa mianem heteroptopii lub atopii, a której istota polega na „wybraniu paru stwierdzeń na temat świata, które wydają się oczywiste i nieredukowalne”, po to, by „następnie [...] poddać je

44. Domańska, Sprawiedliwość epistemiczna..., s. 51.

45. Frederic Jameson, Utopia as Method or the Uses of the Future, w: Utopia/Dystopia: Conditions of Historical Possibility pod red. M.D. Gordin, H. Tilley, G. Prakash, Princeton University Press, Princeton 2010, s. 42-43. cyt. za: Ewa Domańska, Sprawiedliwość epistemiczna..., s. 50.

46. Domańska, Sprawiedliwość epistemiczna..., s. 51.

47. Domańska, Sprawiedliwość epistemiczna..., s. 51. 
podejrzliwym oględzinom, szukając dziur i pęknięc"'48. Jednym z takich stwierdzeń jest to, które dotyczy relacji człowiek-przyroda, i które daje człowiekowi prawo do traktowania jej jako swojej własności. Zgodnie z zasadą gry, podejmujemy próbę wyobrażenia sobie świata, w którym ta zasada nie obowiązuje, i w którym mieszkańcy Heterotopii, Heterotopianie

nie traktują innych istot jako użytecznych przedmiotów i nigdy nie wykorzystują ich dla własnych korzyści. Nie ma mowy o zabijaniu i zjadaniu. To są partnerzy, bliscy. Inni i czasem kłopotliwi, ale jednak bliscy. Heterotopianie zakładają raczej wzajemny szacunek i koegzystencję niż współzawodnictwo i naturalną sprzeczność interesów [...]. To oczywiście powoduje, że od najwcześniejszych lat dzieci uczą się języków innych gatunków, a na uniwersytetach istnieją katedry psychologii międzygatunkowej ${ }^{49}$.

Rola uniwersytetu w kształtowaniu nowej wyobraźni i wyposażaniu młodych badaczy w narzędzia, za pomocą których w przyszłości tym wyobrażonym formom nadawać będą kształty, jest ogromna. I nie chodzi bynajmniej o to, by zbudować świat zaludniony przez samych wegan i weganki - chodzi o to, by na nowo zdefiniować człowieczeństwo w taki sposób, który pozwoli nie tylko na podważenie pozycji antropocentrycznej, ale i na wypracowanie nowych strategii współistnienia. I to właśnie jest jedno z zadań zarówno szeroko rozumianej nowej humanistyki, jak i nowo powstających studiów nad weganizmem, które w postulaty nowej humanistyki wpisują się swoim potencjałem do zaproponowania innej wizji przyszłości. Studia nad weganizmem i weganizacja akademii mogą być postrzegane jako forma przygotowania „podstawy zmian społecznych”, którą to rolę Domańska przypisuje humanistom, artystom i badaczom ${ }^{50}$. Studia nad weganizmem skupiają swoja uwagę między innymi nad sposobami funkcjonowania weganizmu jako "postaci specyficznego imaginarium społecznego" ${ }^{51}$, które Domańska definiuje w kategorii „alternatywnych wizji przyszłości ukazujących różne możliwości współ-bycia i współ-życia społecznego, a także promowanie postaw pożądanych dla realizacji tych możliwości" ${ }^{2}$.

Weganizacja akademii nie wyprowadza badań naukowych na szerokie wody, ze środka których nie widać żadnego brzegu. Nie oznacza zaproszenia do pochylenia się nad naiwnym utopijnym projektem społecznym, który nie ma najmniejszych szans na realizacje (celem weganizmu nie jest przekierowanie ludzkości na dietę roślinną - taki argument często przywoływany jest $\mathrm{w}$ dyskusjach mających na celu

48. Tokarczuk, Moment niedźwiedzia, s. 14.

49. Tokarczuk, Moment niedźwiedzia, s. 19.

50. Domańska, Sprawiedliwość epistemiczna..., s. 51.

51. Domańska, Sprawiedliwość epistemiczna..., s. 43.

52. Domańska, Sprawiedliwość epistemiczna..., s. 43. 
zdyskredytowania diety wegańskiej). Weganizacja akademii jest procesem zmierzającym w kierunku alternatywnej wizji przyszłości i projektem „realistycznej utopii”, którego celem jest wypracowanie alternatywnych form współistnienia, w których rasa, klasa, płeć i wreszcie gatunek nie stanowią czynników skazujących na wykluczenie z obszaru epistemicznej sprawiedliwości. Korzyść wynikająca ze związku humanistyki i weganizmu jest obopólna. Humanistyka potrzebuje weganizacji, by poszerzać swój obszar badawczy tak, aby prowadzone w obrębie humanistyki badania nie ignorowały zjawisk i ideologii nadających kształt współczesności w jej wymiarze jednostkowym i społecznym. Weganizm rozumiany jako pewna ideologia, filozofia i styl życia domaga się coraz energiczniej, aby humaniści pochylili się nad jego potencjałem społecznym i naukowym i wprowadzili refleksję nad kulturowymi, społecznymi i politycznymi aspektami diety roślinnej do akademickiej i poza-akademickiej debaty nad kondycją współczesnego świata i jego ludzkich i pozaludzkich mieszkańców. Być może upłynie bardzo wiele czasu zanim zaczniemy wprowadzać psychologię międzygatunkową do naszych programów nauczania. Wszystko wskazuje jednak na to, że czas na wprowadzanie studiów nad weganizmem właśnie nadchodzi. 